\title{
Evaluasi Maturity Level Sistem Informasi Perpustakaan Berdasarkan Cobit 4.1 pada Domain PO dan ME
}

\section{Evaluation of Maturity Level Library Information System Based on Cobit 4.1 on PO and ME Domains}

\author{
Friden Elefri Neno ${ }^{* 1}$, Kusrini $^{2}$ Henderi $^{3}$ \\ 1,2,3 Magister Informatika STMIK AMIKOM Yogyakarta \\ J1 Ring Road Utara, Condongcatur, Sleman, Yogyakarta 55281 \\ *11nenofriden.e@gmail.com, ${ }^{2}$ kusrini@amikom.ac.id,$\underline{{ }^{3} \text { henderi@mail.ugm.ac.id }}$
}

\begin{abstract}
Abstrak
Penelitian ini membahas tentang evaluasi maturity level sistem informasi perpustakaan dengan Kerangka kerja Cobit 4.1 pada Stimikom Stella Maris Sumba, dengan tujuan untuk mengidentifikasi dan mengetahui permasalahan yang terjadi maka dilakukan audit Sistem informasi pada domain proses yang dipilih yaitu $P O$ dan $M E$ dari kedua proses domain tersebut memiliki tujuan masing-masing yaitu: PO untuk mengukur strategi dan identifikasi TI yang dapat berkontribusi pada pencapaian objektif bisnis dan ME untuk pengawasan, penilaian dan evaluasi yang dilakukan secara berkala dengan memastikan proses TI sehingga dapat berjalan dengan baik. Evaluasi maturity level dimaksudkan untuk mengetahui kendala dan kelemahan pada domain proses yang terpilih. Hasil evaluasi maturity level Sistem Infromasi Perpustakaan Stimikom Stella Maris Sumba ditetapkan dengan maturity level sebesar 2.61 dengan tingkat kematangan level 3 (Defined). Dengan ini membuktikan bahwa pengelolaan TI di Stimikom Stimikom Stella Maris Sumba berada pada tahap dimana pihak manajemen berhasil menciptakan dan mengkomunikasikan standard pengelolaan proses TI dengan baik. Sedangkan tingkat kematangan yang diharapkan (to-be) berada pada level 4 (Managed and Measurable). Untuk mencapai tingkat kematangan yang diharapkan maka diperlukan perbaikan pada masing-masing domain proses sehingga ditingkatkan berdasarkan temuan dan rekomendasi perbaikan.
\end{abstract}

Kata kunci-Evaluasi, maturity level, SI perpustakaan, cobit 4.1, PO, ME

\begin{abstract}
This study discusses the evaluation of the library's information system maturity level with the Cobit 4.1 Framework on the Stella Maris Sumba Stimicom, with the aim of identifying and knowing the problems that occur. Information system audits on the selected process domains are PO and ME of the two domain processes. the objectives of each are: $P O$ to measure strategy and identification of IT that can contribute to the achievement of business objectives and ME for supervision, assessment and evaluation that is carried out periodically by ensuring the IT process so that it can run well. Evaluation of maturity level is intended to determine the constraints and weaknesses in the chosen process domain. The evaluation results of the maturity level Information System of the Stimikom Stella Maris Sumba Library are set with a maturity level of 2.61 with a level 3 maturity level (Defined). This proves that IT management at Stella Maris Sumba Stimikom Stimikom is at the stage where the management has successfully created and communicated the IT process management standards well. While the expected maturity level (to-be) is at level 4 (Managed and Measurable). To achieve the expected level of maturity, improvements in each process domain are needed so that it is improved based on findings and recommendations for improvement.
\end{abstract}

Keyword-Evaluation, maturity level, SI library, cobit 4.1, PO, ME 


\section{PENDAHULUAN}

Berkembangnya teknologi informasi dalam dalam dunia kerja yang membuat banyak perubahan dalam manfaat dan akses kemudahan manusia, yang banyak pekerjaan menggunakan sistem infromasi baik dalam perkantoran pemerintahan dan swasta. Dengan kemajuan ilmu pengetahuan dan teknologi informasi merupakan suatu kebutuhan masyarakat yang sangat penting di era moden sekarang yang mendistribusikan informasi dengan cepat tepat dan efisien.

Perpustakaan diera teknologi sekarang sangat penting yang diterapkan dalam undangundang Nomor 43 tahun 2007 yang memuat tentang perpustakaan adalah tempat untuk penyedia informasi yang digunakan oleh peseorangan,kelompok,masyarakat umum yang menggunakan fasilitas perpustakaan, oleh karena itu perlu ditata dan dikelolah dengan baik dalam membangun dan dikembangkan sesuai dengan tuntutan kebutuhan masyarakat dalam teknologi untuk kepuasan pengguna, oleh karena itu perpustakaan tidak hanya dibatasi dalam pelayanan informasi dalam pengetahuan tetapi juga didukung dengan pustakawan-pustakawan yang handal yang tidak hanya pada professional dalam ilmu pustakaan tetapi memiliki ketrampilan dalam ilmu pengetahuan yang lain dalam meningkatkan kualitas tata kelola sistem informasi perpustakaan yang professional.

Stimikom Stella Maris Sumba saat ini memanfaatkan teknologi informasi dalam menunjang aktifitas akan tetapi sejauh mana atau beberapa besar penggunaan teknolgi informasi yang digunakan yang mampu menunjang proses institusi sampai saat ini belum diketahui maka perlu dilakukan evalausi pada domain (Plan and Organize), ME (Monitor and Evaluate).

Framework Cobit 4.1 merupakan kerangka kerja TI yang dirancangkan oleh ISACA (Information System Audit And Control) yang menjadi alat bantu dalam menyediakan proses dan ukuran indikator untuk membantu perusahaan dalam mengoptimalkan pengelolaan TI dengan mengembangkan control terhadap manajemen TI yang baik dalam penyelarasan tujuan bisnis dan tujuan teknologi informasi untuk pemilihan proses evaluasi internal control TI jika dibandingkan dengan model atau tools lain seperti ITL,COSO,ISO/IEC 17799:2005 [1]

Penelitian yang dilakukan oleh Sandi Kosasi, 2016 tetang Evaluation of Information Technology Governence Implementation in Bussiness Enterprice. Penelitian ini membahas DS5. Penelitian ini untuk mencapai nilai yang konsisten dengan proses domain PO dan DS5 [2]. Pada penelitian ini hanya menyinggung secara garis pada dua domain

Untuk mengetahui tingkat efetivitas perlu dilakukan evaluasi dengan cara mengaudit sistem informasi pepustakaan dengan Framework cobit 4.1. Penelitian yang dilakukan oleh Awalludiyah Ambarwati, 20017 tentang Analisis Maturity Level Business Goals 8 Menggunakan COBIT Pada PT APLIN. Penelitian ini bertujuan memberikan layanan untuk memenuhi kebutuhan pelanggan dan mengetahui maturity level dengan framework cobit 4.1 meliputi tiga proses teknologi informasi, yaitu PO3,AI5 DS6. Pada penelitian ini nilai maturity level dihitung masisng-masing proses IT serta tidak analisa nilai kesenjangan [3].

Penelitian yang dilakukan oleh Winalia, 2017 Pengukuran Tingkat Kematangan Teknologi Informasi Menggunakan Cobit 4.1 Pada Universitas Jenderal Achmad Yani. Tujuan penelitian ini untuk perbaikan kesalahan kinerja sistem informasi dalam penyampaian informasi kepada pengguna dengan evalausi menggunakan cobit 4.1, domain yamg dievaluasi meliputi AI dan ME [4]. Penelitian ini proses pengolahan data IT untuk maturity level tidak ada proses data pada pembahasan tetapi nilai maturity tiap domain ditetntukan dikesimpulan.

Penelitian yang dilakukan oleh Khairan Marzuki,2018 tentang Audit Tata Kelola Teknologi Informasi Menggunakan Cobit 4.1 Domain Monitoring Evaluasi Pada Perguruan Tinggi Swasta. Penelitian ini mengelolah domain Monitoring Evaluasi ME untuk menentukan nilai Maturity level dan kesenjangan [5]. Penelitian ini tidak ada rujukan sebagai rekomendasi perbaikan untuk proses IT yang nilai belum mencapai target.

Penelitian ini menggunakan cobit 4.1 sebagai analis untuk mengevaluasi audit sistem 
informasi karena merupakan panduan standar praktek tata kelola teknologi informasi dikeluarkan oleh IT Governance Institute sebagai bagian dari ISACA (Information System Audit and Control Association) yang digunakan secara global karena memiliki keunggulan dalam kontrol TI membantu manajemen dalam memahami dan mengelola resiko-resiko yang berhubungan dengan Teknologi Informasi (TI)[6].Maturity level untuk mengukur kinerja sistem informasi [7]

\subsection{Alur Penelitian}

\section{METODE PENELITIAN}

Pada penelitian ini dilakukan beberapa tahapan berdasarkan pada gambar 1 berikut ini

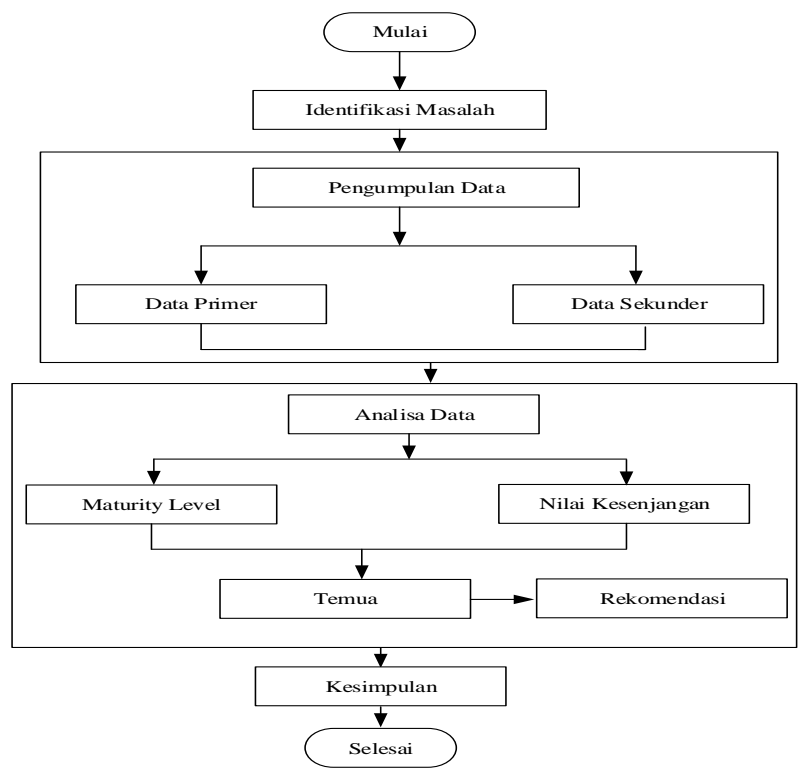

Gambar 1 Metode Penelitian

Berdasarkan gambar alur metode penelitian pada gambar 1 menjelaskan bahwa penelitian dilakukan melalui berapa tahap, yaitu:

a. Identifikasi Masalah

Mengutarakan permasalahan yang akan diidentifikasi

b. Pengumpulan Data

Stategi atau cara yang dipakai oleh peneliti guna mengumpulkan data yang dibutuhkan dalam penelitiannya. Pengumpulan data dalam penelitian dimaksudkan guna mendapatkan bahan, keterangan, kenyataan, dan informasi yang bisa dipercaya. Untuk mendapatkan data seperti yang dimaksudkan tersebut, dalam penelitian bisa dipakai berbagai macam metode, di antaranya, yaitu data primer dan sekunder.

c. Analisa Data

Analisa data merupakan Suatu tahapan proses untuk pengolahan data menjadi sebuah informasi baru agar karakteristik data tersebut menjadi lebih mudah dimengerti dan berguna untuk solusi suatu permasalahan, khususnya yang berhubungan dengan penelitian.

\section{HASIL DAN PEMBAHASAN}

3.1 Penentuan Obyek domain pada proses IT

Domain yang digunakan untuk evaluasi maturity level pada sistem informasi perpustakaan adalah Plan and Oganise (PO) dan Monitor and Evaluate (ME) pada tabel 1,2 
Evaluasi Maturity Level Sistem Informasi Perpustakaan ...

Tabel 1 Plan and Oganise (PO)

\begin{tabular}{ccl}
\hline No & Proses TI & \\
\hline 1 & PO1 & Mendefinisikan rencana strategis TI \\
2 & PO2 & Mendefinisikan arsitektur informasi \\
3 & PO3 & Menentukan arahan teknologi \\
4 & PO4 & Mendefinisikan proses TI, organisasi dan keterhubungannya \\
5 & PO5 & Mengelola investasi TI \\
6 & PO6 & Mengkomunikasikan tujuan dan arahan manajemen \\
7 & PO7 & Mengelola sumber daya TI \\
8 & PO8 & Mengelola kualitas \\
9 & PO9 & Menaksir dan mengelola resiko TI \\
10 & PO10 & Mengelola proyek \\
\hline
\end{tabular}

Tabel 2 Monitor and Evaluate (ME)

\begin{tabular}{ccl}
\hline No & Proses TI & \multicolumn{1}{c}{ Keterangan } \\
\hline 1 & ME1 & Mengawasi dan mengevaluasi kinerja TI \\
2 & ME2 & Mengawasi dan mengevaluasi kontrol internal \\
3 & ME3 & Memastikan pemenuhan terhadap kebutuhan eksternal \\
4 & ME4 & Menyediakan tata kelola TI \\
\hline
\end{tabular}

3.2 Analisa data domain PO dan ME

Sesudah melakukan pengolahan data, dilakukan Analisa data terdiri dari Analisa maturity level saat ini ((as-is), Analisa tingkat kematangan yang diharapkan (to-be) dan Analisa kesenjangan

3.2.1 Analisa maturity level saat ini (as-is)

Model kematangan dimaksudkan untuk mengetahui keberadaan masalah dan bagaimana menentukan prioritas perbaikan. Hasil perhitungan nilai tingkat kematangan adalah indeks kematangan untuk mendapatkan tingkat kematangan berdasarkan pada level 0 sampai level 5 [8] pada Tabel 3

Tabel 3 Kriteria nilai maturity level

\begin{tabular}{cl}
\hline Maturity index & \multicolumn{1}{c}{ Maturity level } \\
\hline $0-0.49$ & 0-Non-Existent \\
$0.51-1.50$ & 1-Initial / Adhoc \\
$1.51-2.50$ & 2-Repeatable but Intutive \\
$2.51-3.50$ & 3-Defined Process \\
$3.51-4.50$ & 4- Managed and Measurable \\
$4.51-5.00$ & 5- Optimized \\
\hline
\end{tabular}

Teknik pengukuran deskripsi dibuat dengan ukuran nominal untuk mengurutkan objek dari yang terendah ke yang tertinggi. Pengukuran dilakukan langsung dari nilai-nilai yang mengacu pada nilai-nilai dari pemilahan keluar dalam model kedewasaan $[9,10]$ seperti yang ditunjukkan pada Tabel 4

Tabel 4. Maturity Level

Maturity level Keterangan




\begin{tabular}{|c|c|}
\hline 0 Existent & $\begin{array}{l}\text { Manajemen Perusahaan tidak peduli dengan pentingnya teknologi } \\
\text { informasi }\end{array}$ \\
\hline 1 Initial & $\begin{array}{l}\text { Perusahaan secara reaktif melakukan aplikasi dan implementasi teknologi } \\
\text { informasi sesuai dengan kebutuhan yang ada secara tiba-tiba, tanpa } \\
\text { didahului oleh perencanaan sebelumnya. }\end{array}$ \\
\hline 2 Repeatable & $\begin{array}{l}\text { Perusahaan memiliki pola yang berulang kali dilakukan dalam } \\
\text { melakukan kegiatan yang berkaitan dengan pengelolaan tata kelola } \\
\text { teknologi informasi, tetapi keberadaannya belum terdefinisi dengan baik } \\
\text { dan masih terjadi inkonsistensi formal }\end{array}$ \\
\hline 3 Define & $\begin{array}{l}\text { Perusahaan telah memiliki prosedur operasi standar formal dan tertulis } \\
\text { yang telah disosialisasikan ke semua tingkat manajemen dan karyawan } \\
\text { untuk dipatuhi dan dikerjakan dalam kegiatan sehari-hari }\end{array}$ \\
\hline 4 Manage & $\begin{array}{l}\text { Perusahaan telah memiliki sejumlah indikator atau ukuran kuantitatif } \\
\text { yang berfungsi sebagai target dan kinerja objektif dari setiap aplikasi } \\
\text { aplikasi teknologi informasi. }\end{array}$ \\
\hline 5 Optimized & $\begin{array}{l}\text { Perusahaan telah menerapkan tata kelola teknologi informasi mengacu } \\
\text { pada "praktik terbaik }\end{array}$ \\
\hline
\end{tabular}

Pada tahap ini dilakukan analisa data untuk menentukan nilai maturity level sistem informasi perpustakaan pada domain PO dan ME. Penilain dilakukan terhadap setiap domain berdasarkan proses IT yang menghasilkan nilai maturity level.

Plan and Oganise (PO)

Tabel 5 Nilai maturity level pada domain Plan and Oganise (PO)

\begin{tabular}{|c|c|c|c|c|}
\hline No & Proses TI & Keterangan & $\begin{array}{l}\text { Nilai } \\
\text { Maturity } \\
\text { Level }\end{array}$ & Level Maturity \\
\hline 1 & PO1 & Mendefinisikan rencana strategis TI & 3.0 & \multirow{3}{*}{$\begin{array}{l}\text { Defined } \\
\text { Defined } \\
\text { Repeatable but } \\
\text { intuitif }\end{array}$} \\
\hline 2 & $\mathrm{PO} 2$ & Mendefinisikan arsitektur informasi & 2.8 & \\
\hline 3 & PO3 & Menentukan arahan teknologi & 2.4 & \\
\hline 4 & $\mathrm{PO} 4$ & $\begin{array}{l}\text { Mendefinisikan proses TI, organisasi dan } \\
\text { keterhubungannya }\end{array}$ & 2.6 & Defined \\
\hline 5 & PO5 & Mengelola investasi TI & 2.5 & Defined \\
\hline 6 & PO6 & $\begin{array}{l}\text { Mengkomunikasikan tujuan dan arahan } \\
\text { manajemen }\end{array}$ & 2.6 & Defined \\
\hline 7 & PO7 & Mengelola sumber daya TI & 2.2 & $\begin{array}{l}\text { Repeatable but } \\
\text { intuitif }\end{array}$ \\
\hline 8 & PO8 & Mengelola kualitas & 2.4 & $\begin{array}{l}\text { Repeatable but } \\
\text { intuitif }\end{array}$ \\
\hline 9 & PO9 & Menaksir dan mengelola resiko TI & 2.7 & Defined \\
\hline 10 & PO10 & Mengelola proyek & 2.6 & Defined \\
\hline & & Rata-Rat & 2.58 & Defined \\
\hline
\end{tabular}

Nilai maturity level pada domain Monitor and Evaluate (ME)

Tabel 6 Nilai maturity level pada domain)Monitor and Evaluate (ME)

\begin{tabular}{cclcc}
\hline No & $\begin{array}{c}\text { Proses } \\
\text { TI }\end{array}$ & \multicolumn{1}{c}{ Keterangan } & $\begin{array}{c}\text { Nilai Maturity } \\
\text { Level }\end{array}$ & $\begin{array}{c}\text { Level } \\
\text { Maturity }\end{array}$ \\
\hline 1 & ME1 & Mengawasi dan mengevaluasi kinerja TI & 2.6 & Defined \\
2 & ME2 & $\begin{array}{l}\text { Mengawasi dan mengevaluasi kontrol } \\
\text { internal }\end{array}$ & 2,7 & Defined \\
\hline
\end{tabular}


Evaluasi Maturity Level Sistem Informasi Perpustakaan ...

\begin{tabular}{cclcc}
3 & ME3 & $\begin{array}{l}\text { Memastikan pemenuhan terhadap kebutuhan } \\
\text { eksternal }\end{array}$ & 2,4 & $\begin{array}{c}\text { Repeatable } \\
\text { but intuitif } \\
\text { Defined }\end{array}$ \\
\hline & ME4 & 2.8 & Mefined \\
\hline
\end{tabular}
gambar 2

Dari nilai maturity level proses TI PO dan ME dibuat presentasinya dalam bentuk grafik

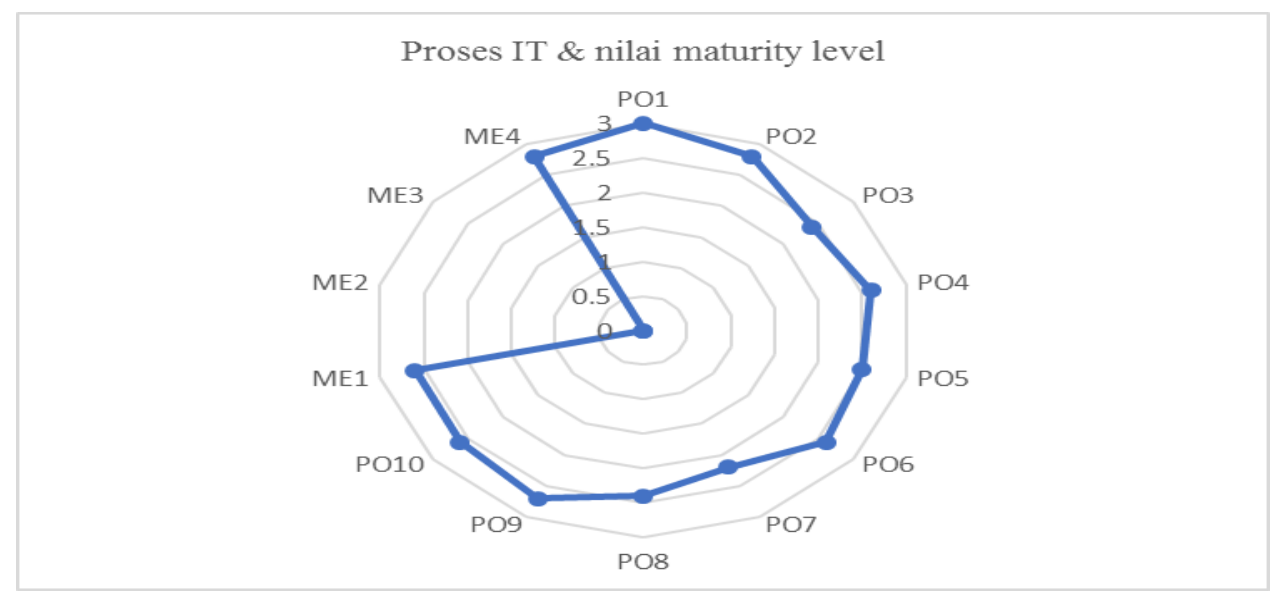

Gambar 2 Grafik nilai maturity level

Tingkat maturity level pengolahan control objective Domain Plan and Oganise (PO) dan Monitor and Evaluate (ME)

Tabel 7 Tingkat maturity level Domain Plan and Oganise (PO) dan Monitor and Evaluate (ME)

\begin{tabular}{|c|l|l|c|c|}
\hline No & $\begin{array}{c}\text { Proses } \\
\text { TI }\end{array}$ & \multicolumn{1}{|c|}{ Keterangan } & $\begin{array}{c}\text { Nilai Maturity } \\
\text { Level }\end{array}$ & Level Maturity \\
\hline 1 & PO & Plan and Oganise (PO) & 2.58 & Defined \\
\hline 2 & ME & Monitor and Evaluate (ME & 2.63 & Defined \\
\hline \multicolumn{2}{|c|}{ Rata-Rata } & 2.61 & Defined \\
\hline
\end{tabular}

Nilai maturity level control objective domain Plan and Oganise (PO) dan Monitor and Evaluate (ME) digambarkan dalam bentuk grafik pai pada gambar 3 


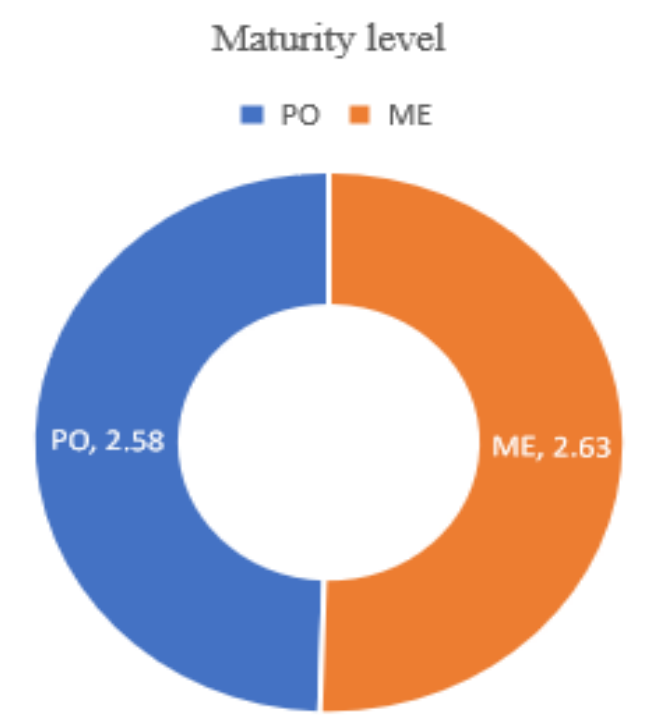

Gambar 3 Grafik maturity level PO dan ME

Nilai Maturity level yang diharapkan (to-be)

Nilai Maturity level yang diharapkan (to-be) dengan tujuan menaikan 1 (satu) level sebagai acuan untuk pengembangan sistem informasi perpustakaan pada Stimikom Stella Maris Sumba.

\subsection{Nilai Kesenjangan (GAP)}

Sesudah mendapatkan nilai maturity level saat ini dan selanjutnya melakukan analisis kesenjangan untuk mengidentifikasi perbaikan yang dilakukan oleh perguruan tinggi agar mencapai level yang diharapkan. Nilai kesenjangan diperoleh dari nilai kesenjangan (GAP) dikurangi nilai matutiry level, seperti pada rumus persamaan [11,12]

$$
\text { nilai kesenjangan }=\mathrm{x}-\mathrm{y}
$$

Keterangan rumus persamaan 2

$\mathrm{X}=$ tingkat kematangan yang diharapkan (to be)

$\mathrm{Y}=$ tingkat kematangan saat ini (as is)

Perbandingan Kesenjangan antara tingkat kematangan domain PO dan ME saat ini dengan yang diharapkan (to-be-as-is) pada tabel 6

Tabel 8 Perbandingan Kesenjangan antara Tingkat Kematangan domain PO dan ME Saat ini dengan yang diharapkan (to-be-as-is)

\begin{tabular}{cccc}
\hline & \multicolumn{3}{c}{ Tingkat Kematangan } \\
\cline { 2 - 4 } Proses IT & $\begin{array}{c}\text { Kematangan Saat } \\
\text { ini }(a s-i s)\end{array}$ & $\begin{array}{c}\text { Kematangan } \\
\text { diharapkan }(t o- \\
b e)\end{array}$ & $\begin{array}{c}\text { GAP(Kematangan } \\
\text { Kematangan Saat ini (as-is) }\end{array}$ \\
\hline PO1 & 3.0 & 4.0 & 1 \\
PO2 & 2.8 & 4.0 & 1.2 \\
PO3 & 2.4 & 3.0 & 0.6 \\
PO4 & 2.6 & 4.0 & 1.4 \\
PO5 & 2.5 & 4.0 & 1.5 \\
PO6 & 2.6 & 4.0 & 1.4 \\
\hline
\end{tabular}


Evaluasi Maturity Level Sistem Informasi Perpustakaan ...

\begin{tabular}{rrrr}
\hline & & 3.0 & \\
PO7 & 2.2 & 3.0 & 0.8 \\
PO8 & 2.4 & 4.0 & 0.6 \\
PO9 & 2.7 & 4.0 & 1.3 \\
PO10 & 2.6 & 4.0 & 1.4 \\
ME1 & 2.6 & 4.0 & 1.4 \\
ME2 & 2,7 & 3.0 & 1.3 \\
ME3 & 2,4 & 4.0 & 0.6 \\
ME4 & 2.8 & 3.71 & 1.2 \\
\hline Rata-Rata & 2.61 & & 1.12 \\
\hline
\end{tabular}

Perbandingan Kesenjangan antara Tingkat Kematangan domain PO dan ME Saat ini dengan yang diharapkan (to-be-as-is) digambarkan dalam grafik radar pada gambar 4

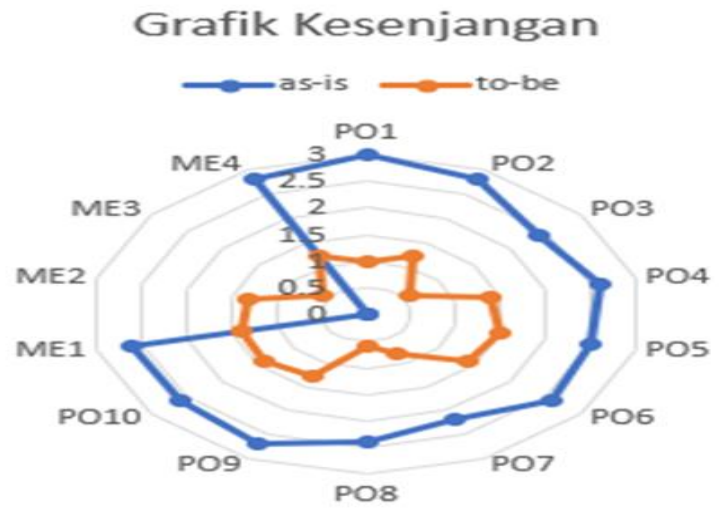

Gambar 4 Kesenjangan saat ini dan yang diharapkan

\subsection{Hasil Temuan}

Berdasarkan hasil evaluasi nilai maturity level pada domain Plan and Oganise (PO) dan Monitor and Evaluate (ME) nilai maturity level yang terendah adalah proses TI PO3menentukan arah teknologi, yaitu 2,4, PO7-mengelolah sumber daya TI, yaitu 2,2, PO8mengelolah kualitas, yaitu 2,4 dan ME3-memastikan pemenuhan terhadap kebutuhan eksternal, yaitu 2,4. Temuan dan kendala yang ditemukan pada Proses IT pada Tabel 9

Tabel 9 Temuan dan kendala yang ditemukan pada Proses IT

\begin{tabular}{|c|c|c|}
\hline $\begin{array}{c}\text { Proses } \\
\text { IT }\end{array}$ & Keterangan & Temuan \\
\hline \multirow{3}{*}{ PO3 } & \multirow{3}{*}{ Menentukan arahan teknologi } & $\begin{array}{l}\text { Perencanaan strategis dalam arah teknologi tidak } \\
\text { tepat dalam tujuan bisnis Perguruan Tinggi }\end{array}$ \\
\hline & & $\begin{array}{l}\text { Rencana infrastruktur teknologi tidak sesuai dengan } \\
\text { rencana strategis }\end{array}$ \\
\hline & & $\begin{array}{l}\text { Tidak ada monitoring dalam dalam pembuatan } \\
\text { perencanaan infrastruktur TI dimasa yang akan } \\
\text { datang }\end{array}$ \\
\hline \multirow{4}{*}{ PO7 } & \multirow{4}{*}{ Mengelola sumber daya TI } & $\begin{array}{l}\text { Rekrutmen personil tenaga kerja tidak memiliki } \\
\text { ketrampilan dan kemampuan TI }\end{array}$ \\
\hline & & $\begin{array}{l}\text { Personil kerja kurang memiliki kompetensi dalam } \\
\text { pendidikannya serta tidak ada pelatihan dan } \\
\text { pengalaman }\end{array}$ \\
\hline & & Tidak ada supervisi dan standard operasional kerja \\
\hline & & Tidak ada evaluasi kinerja karyawan \\
\hline \multirow{2}{*}{ PO8 } & \multirow{2}{*}{ Mengelola kualitas } & Tidak menetapakn sistem manajemen mutu \\
\hline & & Kurang standar manajemen kualitas IT \\
\hline
\end{tabular}




\begin{tabular}{lll}
\hline & & Pengembangan dan Standar Akuisisi \\
& $\begin{array}{l}\text { Layanan kepada pelanggan belum sesuai dengan } \\
\text { kebutuhan }\end{array}$ \\
\cline { 3 - 3 } & $\begin{array}{l}\text { Kurang Pemantauan dan peninjauan dalam melihat } \\
\text { kualitas }\end{array}$ \\
\hline \multirow{2}{*}{ ME3 } & $\begin{array}{l}\text { Memastikan pemenuhan terhadap kebutuhan } \\
\text { eksternal }\end{array}$ & $\begin{array}{l}\text { Tidak ada persyaratan kepatuhan hukum eksternal } \\
\text { dalam kebijakan dan standard prosedur TI }\end{array}$ \\
\cline { 3 - 3 } & Kurang respon terhadap persyaratan eksternal \\
\hline
\end{tabular}

\subsection{Rekomendasi}

Dari hasil temuan dibuatkan rekomendasi atau saran pada domain Plan and Organise (PO) dan Monitor and Evaluate (ME) berdasarkan proses IT pada standard cobit 4.1.

a. Rekomendasi untuk PO3

Manajemen harus memastikan adanya pengembangan dan pemeliharaan perencanaan arah teknologi dengan memperhitungkan dampak potensial dari perubahan dan kemunculan teknologi baru dan didukung anggota staf TI yang memiliki keahlian dan keterampilan untuk mengembangkan rencana infrastruktur teknologi. Menetapkan fungsional yang bertanggungjawab untuk pengembangan dan pemeliharaan untuk pengelolaan rencana infrastruktur teknologi.

b. Rekomendasi untuk PO7

Manajemen perlu kesadaran tentang pentingnya TI untuk menyelaraskan sumber daya TI dengan perencanaan TI dalam Perguruan Tinggi dengan memberikan tanggungjawab kepada sumbr day TI

c. Rekomendasi untuk ME3

Menetapkan pengendalian secara formal dalam setiap kebijakan dan kegiatan, mulai membudayakan memberikan reward kepada individu yang mana untuk memotifasi tindakan yang posetif serta tanggungjawab pengendalian internal diserahkan kepada staf yang lain mendampingi ahli, sehingga secara berlahan pengendalian tidak focus pada satu orang

\section{KESIMPULAN}

Berdasarkan hasil penelitian telah disimpulkan dari beberapa kesimpulan, yaitu

a. Berdasarkan hasil evaluasi maturity level pada domain Plan and Organise (PO) dan Monitor and Evaluate (ME) rata -rata pada 2.58 dan 2.63.

b. Total penjumlahan dari dua domain untuk nilai akhir rata-rata 2.61 yang dikategorikan pada level 3, yaitu defined. Berdasarkan hasil temuan pada proses TI meliputi PO3, PO7, PO8 dan ME3 pihak manajemen memperbaiki berdasarkan ketentuan yang direkomendasikan

c. Penelitian ini menghasilkan nilai evaluasi maturity level pada domain PO dan ME dengan menemukan beberapa temuan dan beberapa rekomendasi yang akan diperbaiki oleh Stimikom Stella Maris Sumba

d. Berdasarkan hasil penelitian yang telah dilakukan, untuk pengembangan penelitian selanjutnya disarankan pemetaan rekomendasi berdasarkan perspektifnya.

\section{SARAN}

Beberapa hal yang diharapkan untuk dikembangkan diwaktu yang akan dating adalah

a. Adanya kesenjangan antara tingkat kematangan saat ini dengan tingkat kematangan yang diharapkan dengan melakukan upaya untuk perbaikan secara terus menerus dimana proses perbaikan ini membutukan seluruh komitmen yang terkait pada Stimikom Stella Maris Sumba 
Evaluasi Maturity Level Sistem Informasi Perpustakaan ...

b. Untuk penelitian selanjutnya diharapkan melakukan penelitian yang akan datang menggunakan domain dan sub domain yang berbeda

\section{UCAPAN TERIMA KASIH}

Penulis mengucapkan terimakasih kepada Sekolah Tinggi Stimikom Stella Maris Sumba yang telah memberi dukungan terhadap seluruh kegiatan penelitian ini

\section{DAFTAR PUSTAKA}

[1] Herlambang, S, dan Tanuwijya ,H, 2005 Sistem Informasi Konsep Teknologi dan Manajemen, Penerbit Graha Ilmu,Yogyakarta

[2] S. Kosasi. 2016. Evaluation of Information Technology Governance Implementation in Business Enterprises. International Conference on Information Management and Technology (ICIMTech), 978-1-5090-3352-2/16/\$31.00 @2016 IEEE2016

[3] Awalludiyah Ambarwati, Ade Putra Habibi. 2017. Analisis Maturity Level Business Goals 8 Menggunakan COBIT Pada PT. APLIN, Jurnal INTENSIF, Vol.1 No.2 Agustus 2017, ISSN: 2580-409X (Cetak) / 2549-6824 (Online)

[4] Winalia, Faiza Renaldi, Asep Id Hadiana, 2017, Pengukuran Tingkat Kematangan Teknologi Informasi Menggunakan Cobit 4.1 Pada Universitas Jenderal Achmad Yani. Seminar Nasional Aplikasi Teknologi Informasi (SNATI), ISSN: 1907 - 5022

[5] Khairan Marzuki,Arief Setyanto,Asro Nasiri, 2018, Audit Tata Kelola Teknologi Informasi Menggunakan Cobit 4.1 Domain Monitoring Evaluasi Pada Perguruan Tinggi Swasta. Seminar Nasional Sistem Informasi dan Teknologi Informasi 2018 (SENSITEK 2018), STMIK Pontianak, 12 Juli 2018,ISSN:2621-0428

[6] Governance Institute. 2007. COBIT 4.1, United States of America

[7] Herison Surbakti,2014. Cobit 4.1 A maturity Level Framework for Measurement of Information System Performance (Case Study : Academic Bureau at Universitas Respati Yogyakarta). International Journal of Engineering Research \& Technology (IJERT), Vol. 3, Agustus 2014, ISSN:2278-0181, pp $999-1004$

[8] Gusti Ayu T K, I Made Sukarsa and I Putu Agung B. 2005. Governance Audit of Application Procurement Using Cobit Framework. Journal of Theoretical and Applied Information Technology (JATIT). Vol 59. No.2. ISSN:1992-8645.2005, pp 342 - 351.

[9] Riyanarto Sarno and Irsyat Iffano, 2009, Information Security Manajemen Sytem, Surabaya: ITS Press ,in Indonesian Language.

[10] Tanuwijaya, Haryanto, Riyanarto Sarno (2010), "Comparation Of COBIT Maturity Model And Structural Equation Model For Measuring The Alignment Between University Academic Regulations And Information Technology Goals”, IJCSNS

[11] Ibnu Dwi Lesmono, Denny Erica.2018. Tata Kelola Teknologi Informasi Dengan Metode COBIT 4.1 (Studi Kasus: PT.IMI). Jurnal Kajian Ilmiah, Volume 18, No. 1, Januari 2018, p-ISN 1410-9794 e-ISSN 2597-792X

[12] S. Ernawati \& N. K. Hikmawati, "An Analisis of information technology on data processing by using cobit framework", 2015 international journal of advance computer scince and application IJACSA 2015, volume 6 No. 9 